PONTIFÍCIA UNIVERSIDADE CATÓLICA dO RIO DE JANEIRO

De que forma o absenteísmo influencia o comportamento dos grupos formais da Unidade Bacia de Campos da Petrobras.

Alexandre Gomes da Silva

Trabalho de Conclusão de Curso

CENTRO de CIÊNCIAS SOCIAIS - CCS

DePARTAMENTO de AdMINISTRAÇÃo

Graduação em Administração de Empresas 
Alexandre Gomes da Silva

\section{De que forma o absenteísmo influencia o comportamento dos grupos formais da Unidade Bacia de Campos da Petrobras.}

Trabalho de Conclusão de Curso

Trabalho de Conclusão de Curso, apresentado ao programa de graduação em Administração da PUC-Rio como requisito parcial para a obtenção do título de graduação em Administração.

Orientador: Professor Marcelo Fernandes Piñeiro.

Rio de Janeiro

Junho de 2016. 
"Nunca considere o estudo como um dever, mas como uma oportunidade invejável para aprender"

(Albert Einstein) 


\section{Agradecimentos}

Primeiramente, eu agradeço a Deus e a toda a minha família junto aos meus amigos, pois foram eles os principais responsáveis pela minha formação profissional, principalmente, a minha mãe que, infelizmente, não teve a oportunidade acadêmica do qual eu tive o privilégio como aluno. Esse registro, da mesma forma, para o meu pai que já faleceu há quase 15 anos e que realizei um sonho dele e de toda minha família. Além disso, eu terei sempre um respeito e um carinho muito grande por essa instituição de excelência, nomeada Puc-Rio, e ao departamento de administração do IAG que não apenas me formou como um grande profissional, mas, também, como um "novo cidadão" cheio de sonhos e objetivos diferentemente do meu passado sombrio e desanimador como é na comunidade em que eu convivo na zona Norte da cidade do Rio de Janeiro. Lembro, bem como, que essa formação será um marco na minha família, um divisor de águas na minha vida e da minha futura família que me espera, entretanto, jamais me esquecerei da responsabilidade em continuar os meus estudos para que eu possa a cada dia melhorar e atualizar as minhas habilidades e reflexões como profissional. Por fim, agradeço, também, ao meu professor orientador Marcelo Fernandes Piñeiro e aos demais professores de toda a minha vida acadêmica, aos meus colegas de graduação e a todos os funcionários do departamento IAG e do campus Puc-Rio. 


\section{Resumo}

DA SILVA, Alexandre Gomes. De que forma o absenteísmo influencia o comportamento dos grupos formais da Unidade Bacia de Campos da Petrobras. Rio de Janeiro, 2016. 37 p. Trabalho de Conclusão de Curso Departamento de Administração. Pontifícia Universidade Católica do Rio de Janeiro.

Este estudo visa entender melhor a importância do "fenômeno" do absenteísmo nas organizações públicas, a partir dos indivíduos e seus respectivos grupos formais, de trabalho, pois cada vez mais as empresas, sejam elas públicas ou privadas, estão se preocupando em manter as suas operações ainda mais eficientes. A partir dessa ótica, foi desenvolvido esse estudo com a finalidade de esclarecer a influência do absenteísmo no comportamento dos grupos da Unidade da Bacia de Campus no departamento de Construção e Montagem, da Petrobras. Além disso, esse estudo foi desenvolvido por meio de pesquisa exploratória e da análise descritiva qualitativa, por isso, foi utilizado como ferramenta de pesquisa o roteiro de entrevista, assim, o autor do estudo chegou à conclusão de que o absenteísmo influencia no comportamento dos grupos formais e, assim, influencia no desenvolvimento dos processos internos, pois gera atrasos na produção das atividades administrativa, principalmente, no despacho dos diversos documentos de análise fiscal e de projetos das plataformas petrolíferas, assim, gerando algum tipo desconforto entre na equipe de trabalho e mudanças na tomada de decisão da chefia na gestão da equipe de trabalho.

\section{Palavras-chave}

Absenteísmo, organizações públicas, grupos formais, comportamento, tomada de decisão

e gestão. 


\section{Abstract}

DA SILVA, Alexandre Gomes. How absenteeism influences the behavior of formal groups of Petrobras in the Campos Basin Unit. Rio de Janeiro, 2016. 37 p. Trabalho de Conclusão de Curso - Departamento de Administração. Pontifícia Universidade Católica do Rio de Janeiro.

This study aims to better understand the importance of the "phenomenon" of absenteeism in public organizations, from individuals and their formal groups, labor, as more companies, whether public or private, are worrying about keeping their more efficient operations. From this perspective, we developed this study in order to clarify the influence of absenteeism in the behavior of Campus Basin Unit groups in the construction and assembly department, Petrobras. In addition, this study was developed through exploratory and descriptive qualitative analysis, so it was used as a research tool the interview script, so the author of the study concluded that absenteeism affects the behavior of groups formal and thus influences the development of internal processes, because it creates delays in the production of administrative activities, particularly in the order of various documents of tax analysis and projects of oil platforms, thus generating some kind discomfort among the work team and changes in management decisionmaking in the work team management.

Key words

Absenteeism, public, formal groups, behavior, decision making and management. 


\section{Sumário}

1. O Problema 1

1.1. Introdução 1

1.2. Objetivo Final 2

1.2.1. Objetivos Intermediários 2

1.3. Delimitação do Estudo 3

1.4. Relevância do Estudo 3

2. Referencial Teórico 4

2.1. A Organização 4

2.1.1. Conceito 4

2.1.2. Tipos de Organização Pública 4

2.2. Agente Público 5

2.2.1. Definição 5

2.2.2. Tipos de Agente Público 5

2.3. Comportamento Organizacional 5

2.3.1. Conceito 5

2.3.2. Modelo Básico de Comportamento Organizacional 6

2.3.3. Indivíduos, Grupos e Estrutura organizacional 8

2.3.4. Grupos Formais e Informais 9

2.3.5. Relação Intergrupos 9

2.3.6. Status do Grupo 11

2.3.7. Diversidade 11

2.3.8. Comunicação Organizacional 11

2.3.9. Comunicação Interpessoal 12

2.3.10. Motivação 12

2.3.11. Ética 14

2.3.12. Percepção Interpessoal 14

2.3.13. Absenteísmo 15

$\begin{array}{lr}\text { 2.3.14. Produtividade } & 16\end{array}$ 
3. Metodologia 17

$\begin{array}{ll}\text { 3.1. Tipo de Pesquisa } & 17\end{array}$

3.2. Seleção de Sujeitos 17

$\begin{array}{ll}\text { 3.3. Coleta de Dados } & 18\end{array}$

3.4. Tratamento dos Dados 18

$\begin{array}{ll}\text { 3.5. Limitações do Método } & 18\end{array}$

4. Apresentação e análise dos resultados 20

4.1. A Organização 20

4.2. Descrição e análise dos resultados das entrevistas 21

4.2.1. Perfil dos entrevistados 21

4.3. Limitações da pesquisa 22

4.4. Descrição e análise dos resultados 24

5. Conclusões e recomendações para novos estudos 32

5.1. Sugestões e recomendações para novos estudos 33

6. Referências Bibliográficas 34

7. Apêndice 36

\section{Lista de figura}

Figura 1 - Contribuições para o estudo do comportamento organizacional. Fonte:

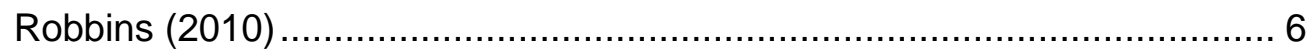

Figura 2 - Modelo básico de comportamento organizacional. Fonte: Robbins

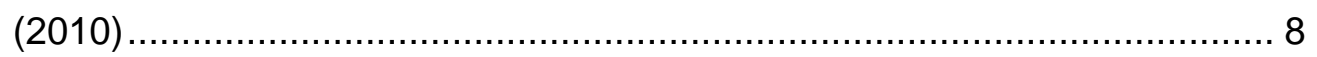

Figura 3 - Tipos de Interdependência intergrupos. Fonte: Bowditch e Buono

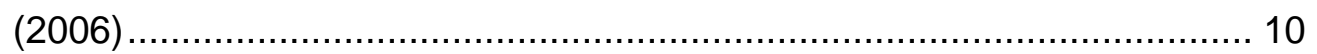

Figura 4 - Comparação dos modelos de motivação de Maslow e Herzberg. Fonte: Chiavenato (2011) .................................................................... 14 
Figura 5 - Organograma da empresa. Fonte: Site da Petrobras. 21

Figura 6: Perfil dos profissionais da Petrobras (gênero). Fonte: Site da Petrobras.

Figura 7: Percentual de entrevistados que conheciam o tema "absenteísmo"... 24

Figura 8: Percentual de entrevistados que já se ausentaram ou não no trabalho. 25

Figura 9: Percentual de entrevistados que entende que de alguma forma 0 fenômeno absenteísmo interfere no desenvolvimento do trabalho. 26

Figura 10: Percentual de respondentes que acreditam que as ausências, dos colegas de trabalho, sejam realizadas por motivo evitável ou inevitável. ... 27

Figura 11: Percentual de entrevistados que percebem a comunicação interpessoal entre os funcionários sobre a ausência dos colegas de trabalho. 28

Figura 12: Percentual de entrevistados a favor e contra uma possível ação de "bonificação" aos funcionários que pouco se ausentam em seus postos de trabalho. 29

Figura 13: Percentual de entrevistados a favor e contra uma possível ação de "punição" aos funcionários que pouco se ausentam em seus postos de trabalho. 30

Figura 14: Percentual de entrevistados que se sentem motivados para não se ausentarem no seu ambiente de trabalho. 31 


\section{O Problema}

\subsection{Introdução}

Segundo publicação de Souza W., no Brasil, o serviço público surge em 1808 , quando a corte portuguesa se instala na cidade do Rio de Janeiro. A partir disso, iniciou-se a consciência da importância do funcionalismo público administrativo e da diplomacia real portuguesa com a colônia brasileira. Em seguida, o concurso público nasce no Brasil, no decorrer do século XX, com a Constituição Federal Brasileira junto com as diversas empresas estatais brasileiras, entre elas a Petrobras que em 1953 foi criada por Getúlio Vargas.

Atualmente, de acordo com publicação de Araújo L., nas organizações públicas sejam elas públicas, subsidiárias ou de sociedade econômica mista, como a Petrobras, existem, basicamente, quatro tipos de agentes públicos, são eles: os funcionários estatutários que prestam serviços para o Governo seja ela da esfera da União, dos Estados ou dos Municípios, além disso, esses funcionários são ingressados através de concursos públicos e possuem um contrato de "posse" segundo a constituição brasileira, já os funcionários celetistas são aqueles que ingressam nas organizações públicas, também, através de concursos públicos, entretanto, possuem seu contrato de trabalho regido pela CLT (Consolidação das Leis do Trabalho); e por fim, os funcionários terceirizados e temporários que são aqueles agentes públicos contratados e regidos através, do mesmo modo, do regime da CLT por um determinado período de contrato ou não de trabalho.

Segundo a revista Proteção, o absenteísmo ${ }^{1}$ nas organizações, em geral, sempre foi um motivo de preocupação, principalmente, para as organizações públicas, ainda mais quando esse fenômeno se aplica ao comportamento da organização como um todo. Ainda segundo a publicação, em 2011, foi realizada pesquisa com mais de 200 empresas do Estado do Rio de Janeiro, sendo a sua maioria na região metropolitana, o fenômeno do absenteísmo representa cerca

\footnotetext{
${ }^{1}$ Absenteísmo é a ausência do funcionário no local de trabalho, (Robbins, 2010).
} 
de $45 \%$ das faltas de trabalho, ou seja, as ausências sem justificativa prévia. Sendo a maioria por cirurgias, lesões e patologias como, por exemplo, doenças contagiosas, depressão e tendinite. Nas organizações públicas, a ausência dos funcionários nos postos de trabalho é uma constante, entretanto, o comportamento dos funcionários públicos, em geral, revela uma peculiaridade, pois ao serem denominados os "intocáveis" pela política de ingresso do cargo público concursado, esses agentes públicos, talvez, ficam desmotivados na sua rotina de trabalho, por consequência, podendo afetar diretamente na produtividade da organização. Além disso, os gestores públicos muitas vezes se escondem atrás da legislação fazendo parte desse processo. Com isso, os grupos formais podem afetar no comportamento organizacional das empresas como um todo. Sendo assim, essa problemática pode ser compreendida pelos administradores como uma oportunidade para entendermos melhor os grupos.

É de fundamental importância que possamos entender o comportamento dos grupos formais para que, assim, possamos compreender melhor o fenômeno do absenteísmo e qual a sua influência dentro da organização. A partir disso, o estudo pretendeu responder o questionamento a seguir: De que forma o absenteísmo influencia o comportamento dos grupos formais da Unidade Bacia de Campos da Petrobras?

\subsection{Objetivo Final}

O objetivo do estudo é entender de que forma o fenômeno "absenteísmo" influencia no comportamento dos grupos formais, no departamento de Construção e Montagem, da Unidade Bacia de Campus da Petrobras?

\subsubsection{Objetivos Intermediários}

- Identificar os grupos formais;

- Entender as características e o comportamento dos grupos;

- Compreender o absenteísmo dos grupos;

- Sugerir ao departamento de estudo possíveis ações para a melhoria do comportamento dos grupos para a diminuição do absenteísmo no setor. 


\subsection{Delimitação do Estudo}

O estudo foi direcionado apenas a dois tipos funcionários da empresa de Sociedade Mista, Petrobras, sendo eles: os celetistas (concursados) e os terceirizados (contratados) que trabalhem na Petrobras realizando atividades administrativas, portanto, sejam elas operacionais ou gerenciais. Além disso, não houve restrição de gênero, idade, raça, classe social, cultural ou religiosa.

A Petrobras é a maior empresa brasileira, segundo notícia publicada pela revista Exame, em julho de 2015, por isso foi escolhida entre todas as organizações públicas como base do estudo.

Com relação à unidade da estatal delimitada foi selecionada à unidade da Bacia de Campos, localizada na cidade de Macaé/RJ (conhecida como a "Capital Nacional do Petróleo"), norte fluminense. Além disso, o departamento delimitado foi o CM (Construção e Montagem), que é apenas um dos diversos departamentos da unidade, e onde se encontram os setores de projetos e de obras, entretanto, o setor analisado foi o setor de projetos.

\subsection{Relevância do Estudo}

O estudo é importante, principalmente, para a gestão gerencial do setor pesquisado, pois ao entendermos melhor o absenteísmo nos grupos formais, os gestores responsáveis poderão compreender melhor a influencia do comportamento desses grupos na organização. 


\section{Referencial Teórico}

\subsection{A Organização}

\subsubsection{Conceito}

Segundo Chiavenato (2011, p.271), "as organizações são concebidas

como unidades sociais (ou agrupamentos humanos) intencionalmente constituídas e reconstruídas a fim de atingir objetivos específicos". Portanto, a organização pode ser entendida como um conjunto de pessoas que de maneira ordenada pretendem atingir objetivos em comum. Além disso, existem três tipos básicos de organizações, por exemplo, as organizações de bens e serviço (ex:: comércio e indústria), as organizações de benefícios mútuos (ex.: nãogovernamental e sindicato) e as organizações públicas (ex.: empresa pública e sociedade de economia mista).

\subsubsection{Tipos de Organização Pública}

De acordo com publicação de Pires B. (2012), as organizações públicas, também chamadas de empresas estatais, são aquelas denominadas as empresas sob o controle do Estado, seja ela Governo Federal, Estadual ou Municipal, e que possuem poderes diretos ou indiretos sobre essas organizações. Ainda segundo o autor, as organizações públicas estão divididas como empresas públicas que são organizações totalmente integralizadas e geridas pelo Governo (ex.: Caixa Econômica Federal), empresas de sociedade econômica mista que são empresas que possuem seu capital majoritariamente pertencente ao Estado (ex.: Petrobras), as empresas subsidiárias (ex.: Petrobras Distribuidora) e as empresas controladas, direta ou indireta, que possuem totalmente ou sua maior parte do capital social no poder do Estado (ex: BNDES). 


\subsection{Agente Público}

\subsubsection{Definição}

Segundo publicação de Araújo L. (2015), um agente público é qualquer um cidadão que atue a serviço da sociedade como um todo, ou seja, aquele indivíduo que está a serviço da administração pública, seja através de um determinado cargo, emprego ou função nas diversas esferas do Governo seja ela da União, Estado ou Município.

\subsubsection{Tipos de Agente Público}

De acordo com a publicação de Souza W. (2013), existem quatro tipos de agente público, são eles: os agentes públicos estatutários que são aqueles que atuam num cargo público em "termo de posse" e por isso não são regidos por meio de um contrato, portanto, o seu regime é investido por um estatuto e não por meio de um contrato formal de trabalho. Já os agentes públicos celetistas, "empregados" que de fato são regidos pela CLT, sejam eles temporários ou não, ao contrário dos agentes estatutários, são regidos através do contrato de Consolidação das Leis de Trabalho (CLT). Por fim, os funcionários terceirizados que são os agentes públicos com contrato de trabalho regidos pela CLT, por fim, os funcionários temporários que não possuem um vínculo de cargo público e o seu período de trabalho é determinado.

\subsection{Comportamento Organizacional}

\subsubsection{Conceito}

De acordo com Robbins, Judge e Sobral (2010, p. 7), "o comportamento organizacional é um campo de estudos que investiga o impacto que indivíduos, grupos e a estrutura organizacional têm sobre o comportamento das pessoas dentro das organizações, com o propósito de utilizar esse conhecimento para melhorar a eficácia organizacional", assim, o comportamento organizacional interpreta o que os indivíduos fazem nas organizações e de que maneira esse comportamento atinge o ambiente da empresa. 
Por fim, ainda segundo os autores, o comportamento organizacional não é somente interpretado por um campo de estudo das ciências sociais, mas também da Psicologia, da Psicologia social, da Sociologia e da Antropologia.

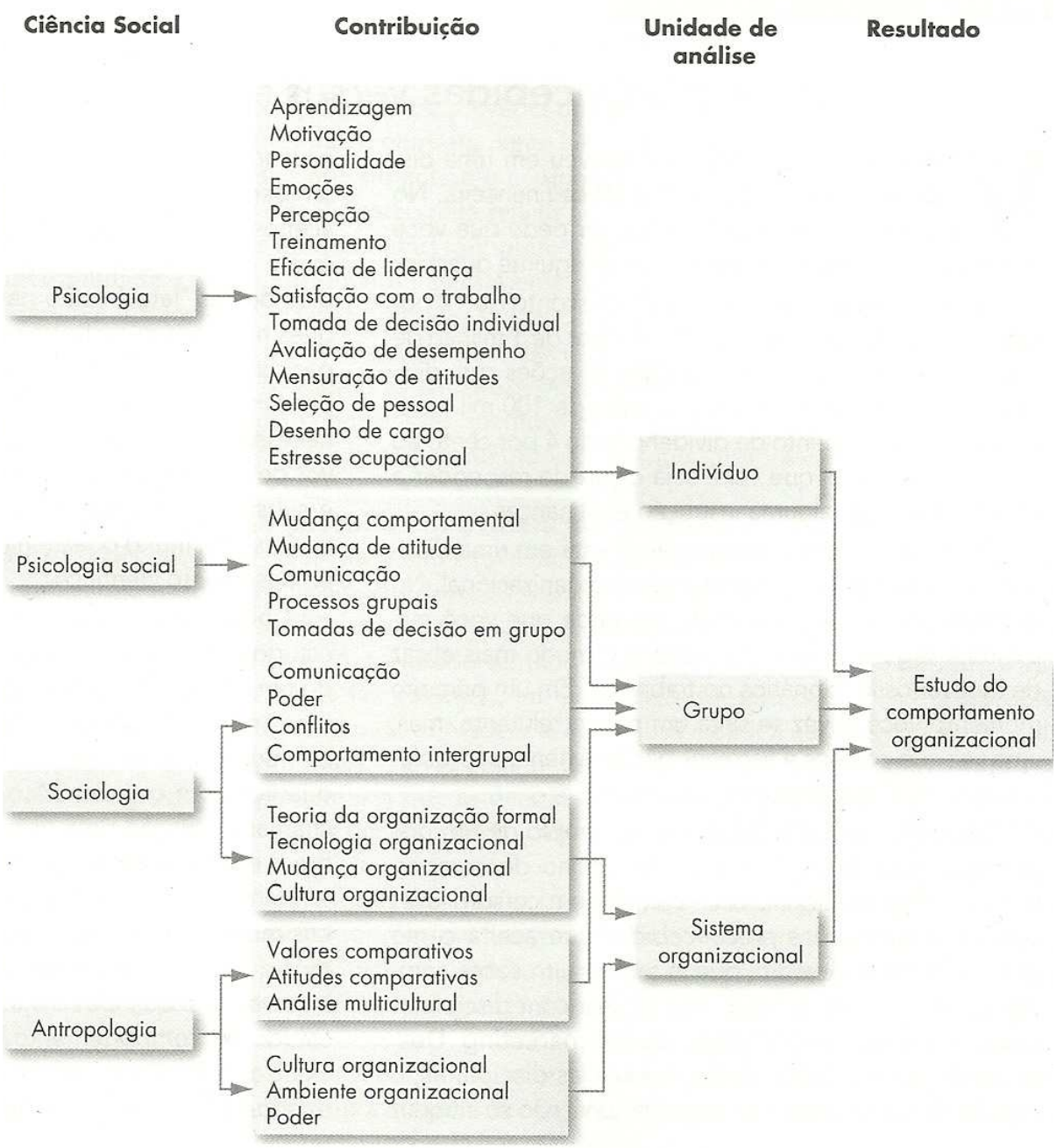

Figura 1 - Contribuições para o estudo do comportamento organizacional. Fonte: Robbins (2010)

O estudo do comportamento organizacional, portanto, aproveitou-se dos conhecimentos de diversas áreas das ciências sociais e humanas, citadas na Figura 1, para a elaboração e contribuição do seu entendimento.

\subsubsection{Modelo Básico de Comportamento Organizacional}

Segundo Robbins, Judge e Sobral (2010), existem seis tipos de variáveis dependentes determinantes no desvio do comportamento organizacional. São elas: 
- Produtividade - a empresa é produtiva quando ela consegue alcançar seus objetivos, assim, transformando os seus insumos em produto de menor custo;

- Absenteísmo - a ausência do funcionário ao local de trabalho;

- Rotatividade - a saída constante dos funcionários da empresa;

- Desvios de comportamento - que leva em questão o custo do absenteísmo e a rotatividade que causam, posteriormente, desvios de conduta dos funcionários;

- Comportamento da cidadania organizacional - não faz parte da competência funcional, entretanto, é discricionário e ajuda na promoção do funcionalismo eficaz da empresa;

- Satisfação do trabalho - uma coleção de sentidos que um indivíduo possui com o seu local de trabalho.

A partir dessas variáveis dependentes, os autores descrevem, também, as variáveis independentes que são de três níveis de possíveis causas para essas variáveis. São elas:

- Variável no nível Individual - atreladas ao comportamento dos funcionários em geral;

- Variável no nível de grupo - no que diz respeito ao entendimento da dinâmica do comportamento de um grupo;

- Variável no nível de sistema organizacional - é o nível mais elevado do comportamento da organização, pois a ela é toda a estrutura formal a respeito do comportamento dos indivíduos e grupos da empresa como um todo.

Por fim, a literatura dos autores descreve o "Modelo Básico de Comportamento Organizacional" na ilustração seguinte: 


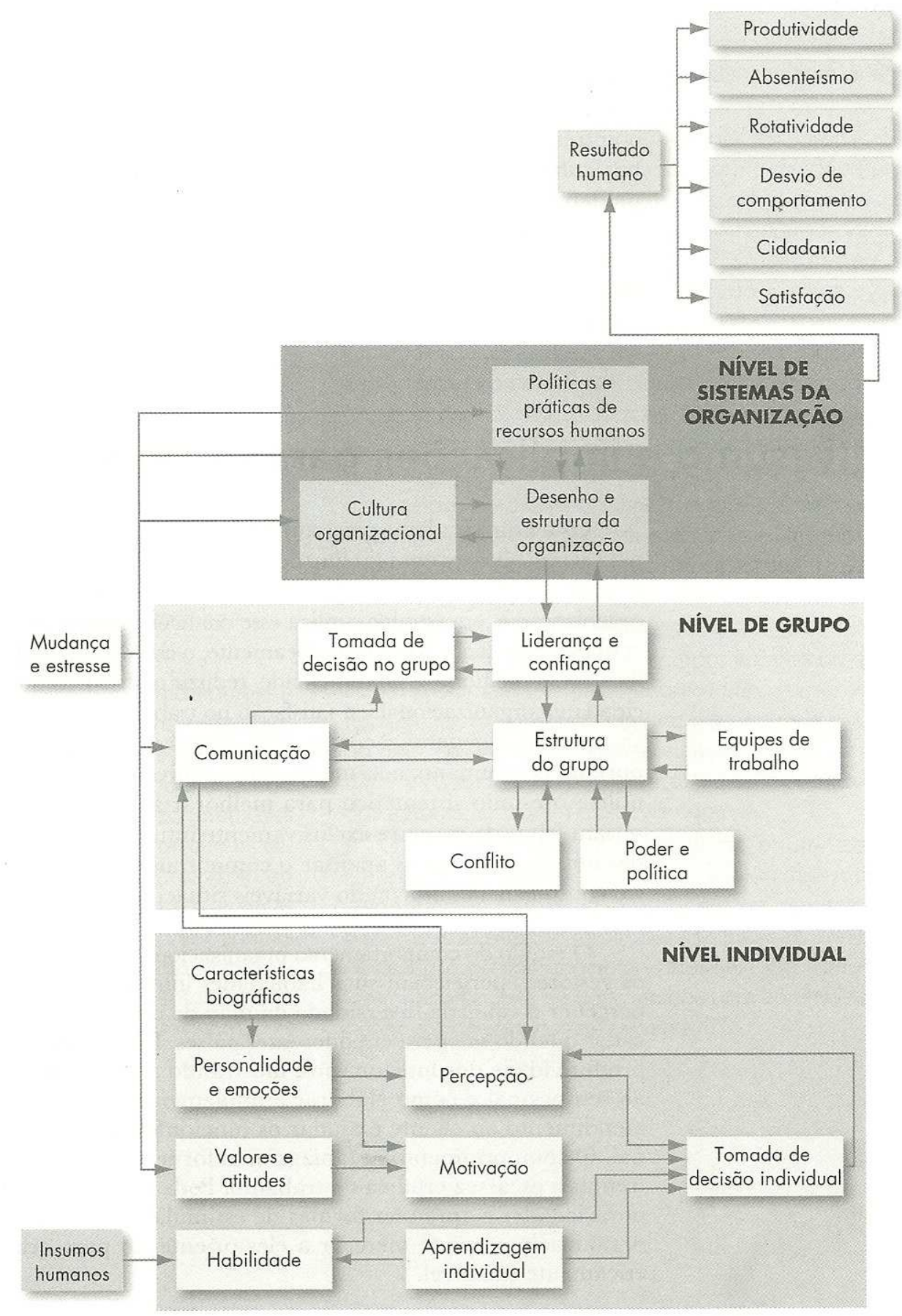

Figura 2 - Modelo básico de comportamento organizacional. Fonte: Robbins (2010)

\subsubsection{Indivíduos, Grupos e Estrutura organizacional}

Segundo Robbins, Judge e Sobral (2010), os indivíduos, dentro das organizações, são pessoas independentes que representam uma unidade social, por isso eles possuem uma grande importância na formação dos grupos. Por 
outro lado, um grupo é definido por duas ou mais pessoas independentes que compartilham um determinado objetivo. Além disso, existem, basicamente, dois tipos de grupos, são eles: os grupos formais são aqueles pré-definidos pela empresa e os grupos informais que são aqueles formados através de relacionamentos dentro das organizações.

Ainda segundo os autores, a estrutura organizacional é definida de forma que as atividades de trabalho sejam organizadas de uma maneira formal através da divisão, agrupamento e coordenação dessas tarefas. Além disso, segundo DuBrin (2003), esse sistema organizacional (estrutura) possui uma interligação, pois tanto os indivíduos quanto os grupos estão o tempo todo influenciando uns aos outros, seja através das relações formais, informais e/ou cultural.

\subsubsection{Grupos Formais e Informais}

Os grupos são entendidos por uma composição de um ou mais indivíduos interdependentes e iterativos, que se agrupam para um determinado objetivo. Esses grupos ainda podem ser formais, informais, de comando, de tarefa, de interesse ou de amizade, (ROBBINS, JUDGE E SOBRAL, 2010).

Os grupos formais, que são o foco deste estudo, são formados a partir de um contexto de alinhamento com a estrutura organizacional da empresa. Por outro lado, os grupos informais são aqueles que não são formados por uma estrutura organizacional definida, mas que aparecem com a necessidade de integração social, (ROBBINS, JUDGE E SOBRAL, 2010).

Segundo Bowditch e Buono (2006), esses grupos formais e informais podem ser constituídos por um mesmo número de indivíduos ao mesmo tempo como, por exemplo, um departamento de recursos humanos que é um grupo formal que possuem objetivos e metas em comuns, entretanto, se os funcionários desse mesmo departamento se reunir com certa frequência, esse grupo será considerado informal por possuírem objetivo de relação social.

\subsubsection{Relação Intergrupos}

A relação entre os grupos é conceituada como uma série de grupos que operam integrados nos diversos níveis da hierarquia, portanto, para entender melhor o comportamento de um departamento, precisamos compreender além das interações dos membros de um determinado grupo, mas também a relação 
entre os outros setores da organização, bem como as interações entre a organização e os seus stakeholders, (BOWDITCH e BUONO, 2006).

A interdependência entre os grupos, ou seja, a extensão da ação de um grupo sobre outro possui quatro tipos básicos de interdependência, (BOWDITCH e BUONO, 2006). São elas:

- Agrupada - é a que descreve um cenário em que os grupos operam em linhas paralelas, assim, é a que compartilha recursos em comum, realizando assim a mesma tarefa que é coordenada hierarquicamente por um determinado grupo.

- Sequencial - é uma situação em que o grupo tem que aguardar a realização da tarefa do outro grupo para poder dar início.

- Recíproca - refere-se ao trabalho compartilhado entre os grupos continuamente, portanto entende-se como uma interdependência mútua entre os grupos envolvidos.

- De equipe - é aquela que os grupos interagem entre si dentro da organização.

Agrupada

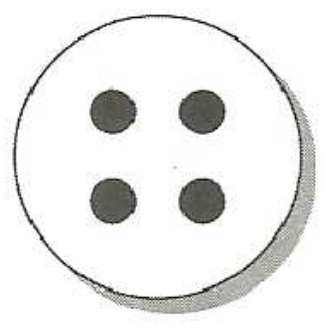

Recíproca

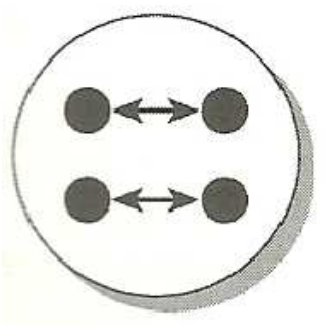

Seqüencial

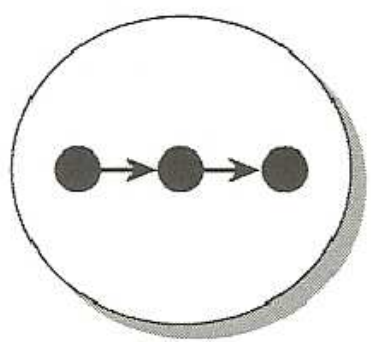

De Equipe

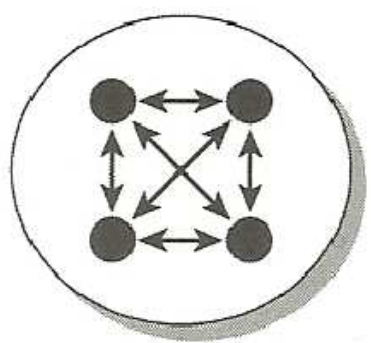

Figura 3 - Tipos de Interdependência intergrupos. Fonte: Bowditch e Buono (2006) 


\subsubsection{Status do Grupo}

Entende-se que ao analisarmos os grupos formais dentro de uma organização veremos status entre esses grupos, pois uns terão mais influência sobre os demais pela distribuição de tarefas, pois um determinado grupo depende do outro, sendo assim, quanto mais poder legítimo tiver um determinado grupo de trabalho, maior será a sua influência sobre os demais grupos que por sua vez terão as suas ações dependentes deles, (COHEN e FINK, 2003)

\subsubsection{Diversidade}

Segundo Robbins, Judge e Sobral (2010), entende-se que diversidade é tudo aquilo que nos diferencia de alguma coisa. A respeito das relações humanas nas organizações, entende-se que elas podem ser de diversos tipos, como: cultural, racial, de gênero, social, religiosa, entre outras. Além disso, existem duas maneiras de entendimento da diversidade. São elas:

- Diversidade em nível superficial - diferenças em características biográficas que se identificam como: gênero, idade, raça, deficiência, orientação sexual e religião;

- Diversidade em nível profundo - diferenças entre preferências, valores e personalidade que ao longo do tempo determinam similaridade à medida que os indivíduos vão se relacionando.

\subsubsection{Comunicação Organizacional}

Segundo Robbins, Judge e Sobral (2010), as redes formais na organização são complexas demais, pois são compostas por vários indivíduos de diferentes níveis hierárquicos. Essas redes são compostas por três tipos comuns, que são: tipo cadeia, tipo roda e do tipo todos os canais.

A estrutura em roda simplifica uma emergência eventual do líder de um grupo, a rede de todos os canais é mais eficiente para uma melhor satisfação dos indivíduos inseridos no grupo e a rede de cadeia é mais apropriada quando necessitamos transmitir um conteúdo com precisão. Entende-se que cada uma dessas redes irá interagir melhor em uma determinada ocasião. Além disso, 
existe também a rede de rumores, que é definida como um sistema de comunicação da organização, (ROBBINS, JUDGE E SOBRAL, 2010).

\subsubsection{Comunicação Interpessoal}

De acordo com Bowditch e Buono (2006, p. 78), "a comunicação é um processo essencialmente interativo de uma pessoa com a outra. Trata-se de um processo transacional dinâmico, no qual os indivíduos constroem significado e alimentam expectativas quanto a suas experiências, quanto ao que está ocorrendo e quanto ao mundo à sua volta, e então compartilham esses significados e expectativas uns com os outros por meio da troca de símbolos".

Esses símbolos podem ser de duas formas: verbal através das palavras ou pode ser não-verbal que é a comunicação através dos gestos e expressões (emoções e sentimentos). Sendo assim, Bowditch e Buono (2006) descrevem que a comunicação interpessoal apresenta cinco funções básicas. São elas:

- Controle - padronizar a comunicação, impor autoridade e responsabilidade;

- Informação - colocar em execução ordens e instruções;

- Motivação - influenciar outras pessoas, compreender diferentes metas e objetivos;

- Emoção - expor emoções e sentimentos;

- Desenvolvimento - compartilhar conhecimento para prover atitudes, comportamentos e crenças.

Portanto, a comunicação interpessoal possui inúmeros objetivos que são utilizados para diversos motivos, e não necessariamente para um determinado objetivo.

\subsubsection{Motivação}

Segundo DuBrin (2003), a motivação é o meio pelo qual o comportamento é estimulado e incentivado no interesse da realização dos objetivos organizacionais, portanto, identificamos que um indivíduo é motivado quando de fato a pessoa despende sacrifício para o atingimento das metas.

Algumas das teorias clássicas da necessidade de motivação como a "hierarquia das necessidades" e a "teoria dos dois fatores" de Maslow e 
Herzberg, respectivamente, apresentam pontos de concordância, pois os fatores higiênicos de Herzberg se semelham com as necessidades primárias de Maslow que são: as necessidades fisiológicas, de segurança e social. Além disso, os fatores motivacionais de Herzberg, também, se relacionam com as necessidades secundárias de Maslow que são: a necessidade de estima e a necessidade de autorealização. Portanto, a Hierarquia das necessidades de Maslow descreve que as necessidades humanas estão ordenadas e dispostas em cinco níveis de acordo com a "pirâmide", da ilustração abaixo, sendo que na parte inferior encontram-se as necessidades fisiológica (necessidades básicas), segundo Chiavenato (2011), composta por:

- Necessidades fisiológicas: que seria a alimentação, o repouso, o abrigo, o desejo sexual, por exemplo;

- Necessidades de segurança: estabilidade, privação, fuga ao perigo, por exemplo;

Já no topo, ainda segundo o autor, as necessidades de autorealização (necessidades mais elevadas) seriam compostas por:

- Necessidades sociais: necessidade de associação, de participação, de amizade, por exemplo.

- Necessidade de estima: seria a autoconfiança, necessidade de aprovação social, de status, de prestígio, por exemplo;

- Necessidade de autorealização: está atrelada a necessidade de autodesenvolvimento contínuo e a sua realização de seu potencial, por exemplo.

Já Herzberg, ele desenvolveu a teoria dos dois fatores para entender o comportamento dos indivíduos no ambiente de trabalho, entretanto, entendendo que as condições de satisfação das pessoas são gerenciadas e administradas pelas organizações nos fatores higiênicos e nos fatores motivacionais estão relacionadas com a natureza das tarefas que os indivíduos executam. Chiavenato (2011). Portanto, os dois fatores são:

- Fatores higiênicos (ou fatores extrínsecos): fatores influenciados seriam os salários, benefícios, supervisão, condições estruturais, clima de relacionamento entre a organização e seus funcionários, por exemplo; 
- Fatores motivacionais (ou fatores intrínsecos): seria o reconhecimento profissional, a autorealização, satisfação no cargo, por exemplo.

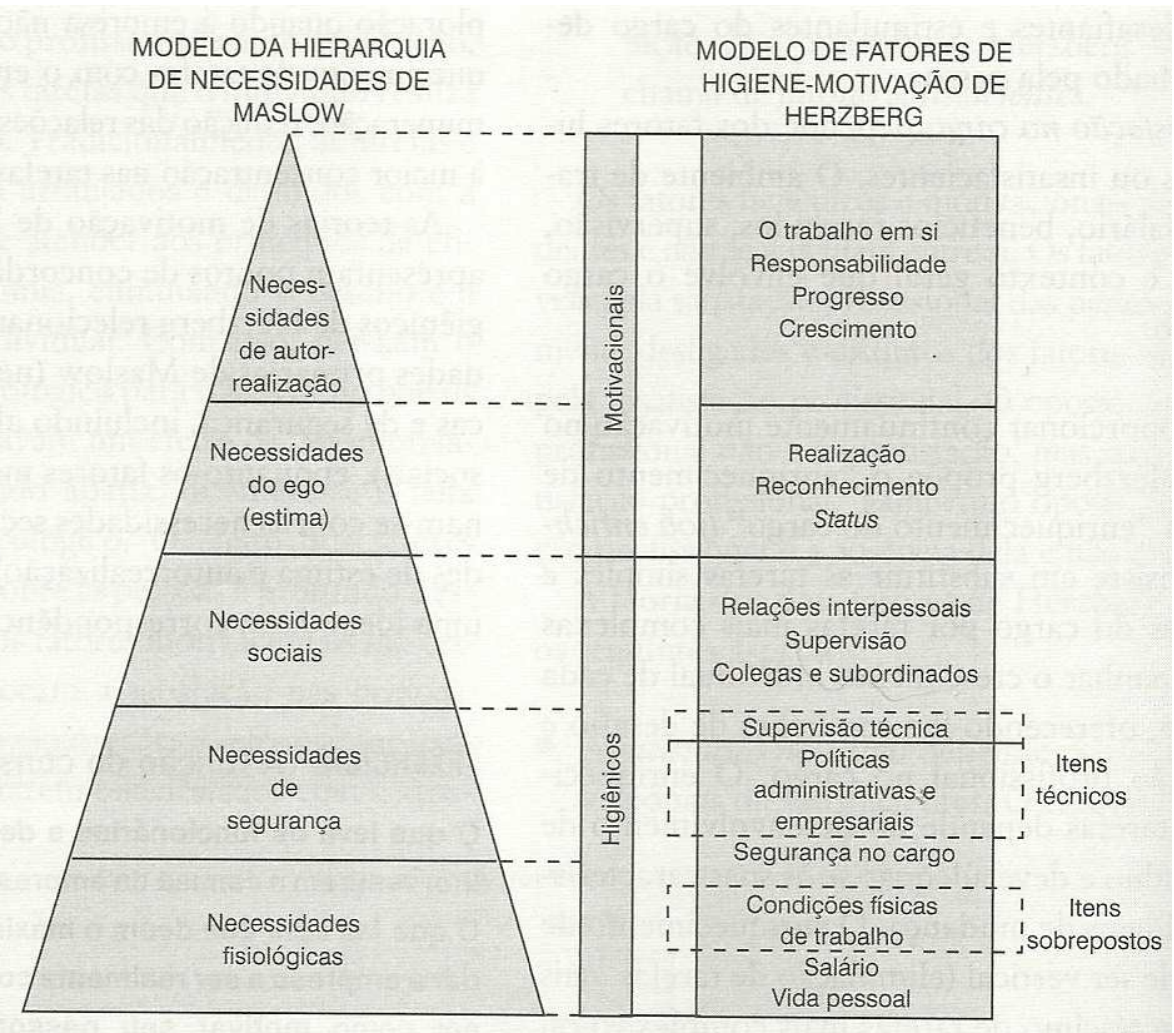

Figura 4 - Comparação dos modelos de motivação de Maslow e Herzberg. Fonte: Chiavenato (2011).

\subsubsection{1. Ética}

A ética se caracteriza no entendimento das crenças dos individuais sobre o que é certo e o que é errado, portanto, a ética pode ser entendida como um veículo que transforma valores em atitudes. O comportamento ético dos indivíduos dentro de uma organização é visto de uma forma ampla, seja dentro ou fora da empresa, pois esses indivíduos, em sua maioria, podem influenciar na visão da organização como um todo, (DUBRIN, 2003).

\subsubsection{Percepção Interpessoal}

Segundo Bowditch e Buono (2006), pessoas diferentes exercem reações a diversos tipos de práticas organizacionais e gerencias, pois, pessoas diferentes se diferenciarão de acordo com a sua intensidade e interpretação de importância que se atribuem aos fatos intrínsecos. 
Ainda segundo os autores, essa percepção está relacionada aos fenômenos visuais e auditivos distintos e é interferida por vários fatores internos e externos, "a percepção que temos de outras pessoas e de situações sociais é também um processo dinâmico", (BOWDITCH e BUONO, 2006, p. 31).

\subsubsection{Absenteísmo}

"O trabalhador só se sente a vontade no seu tempo de folga, porque o seu trabalho não é voluntário, é imposto, é trabalho forçado."

Karl Marx

De acordo com a literatura do autor Chiavenato (2010), o Absenteísmo, ou também chamado de ausentíssimo, é a frequência e/ou duração do período de trabalho inutilizável, ou seja, quando os funcionários de uma organização não comparecem ao seu posto de trabalho. Ainda segundo o autor, o absenteísmo é formado a partir da soma dos períodos em que os seus funcionários se encontram fora do trabalho, seja ela pela ausência, atraso ou por qualquer que seja algum motivo interveniente.

Possuir funcionários nem sempre é sinônimo de tê-los trabalhando durante todos os momentos do trabalho. As ausências dos funcionários provocam certas distorções quando se referem ao volume $\mathrm{e}$ disponibilidade da força de trabalho, (CHIAVENATTO, 2010).

Portanto, o absenteísmo pode ser entendido, basicamente, de duas formas: absenteísmo evitável que seria através do atraso no horário de trabalho, ausência dos funcionários no expediente antes e depois do almoço, saídas antecipadas no expediente etc. Por outro lado, o absenteísmo inevitável seria caracterizado pela ausência por motivo de acidente de trabalho e de doença, entretanto, com justificativa (atestado médico), por exemplo. (CHIAVENATTO, 2010)

Segundo artigo publicado pelo RH Portal, em 2015, nas organizações, quando as atividades são interrompidas por causa da ausência de algum profissional da organização, assim, descontinuando a sinergia operacional, as tarefas são prejudicadas, portanto, medidas importantes poderiam ser tomadas. O fenômeno quase sempre é a conseqüência disso, por isso deve-se ser diagnosticado o mais rápido possível pelos gestores para um melhor gerenciamento da equipe de trabalho. 


\subsubsection{Produtividade}

Segundo Cohen e Fink (2003), toda organização está interessada na sua produtividade, pois ela é muito mais do que um simples indicador econômico, mas, similarmente, utilizada para entender melhor determinados grupos que desempenham suas tarefas de sua competência a modo a satisfazer tanto os clientes dentro como fora da empresa.

As pessoas possuem diferenças individuais que interferem diretamente na sua maior parte do tempo no seu comportamento dentro do ambiente de trabalho. $\mathrm{O}$ autor identifica oito consequências de diferenças entre os indivíduos, entre elas está a "diferenciação em produtividade" que ele descreve como uma análise abrangente das diferenças das pessoas, pois cada ser humano possui o seu próprio desempenho perante uma determinada tarefa, (DUBRIN, 2003). 


\section{Metodologia}

\subsection{Tipo de Pesquisa}

O objetivo deste estudo foi alcançado por meio de uma pesquisa exploratória, que "têm como objetivo proporcionar maior familiaridade com o problema, com vistas a torná-lo mais explícito ou a construir hipóteses", (GIL, 2002). Assim, pretendeu-se buscar os dados e as informações através de pesquisa bibliográfica e entrevista individual, padronizada, sobre 0 comportamento dos indivíduos e seus respectivos grupos, composto por: funcionários celetistas e terceirizados, logo, a pesquisa foi realizado de modo qualitativo.

Segundo Gil (2002), as pesquisas descritivas possuem o objetivo principal a descrição das características dos indivíduos ou de um determinado fenômeno, além disso, pode ser utilizada como ferramenta de relação entre duas variáveis, por exemplo. Portanto, a pesquisa descritiva ocorrerá através do levantamento das informações coletadas a partir da análise dos dados do roteiro de entrevista com a finalidade de condensar esses dados que identifiquem a influência do absenteísmo dos grupos na produtividade da organização.

\subsection{Seleção de Sujeitos}

O universo de interesse deste estudo é formado por funcionários da Petrobrás, com idade igual ou acima de 18 anos, independente de sua inserção cultural, social ou religiosa. Além disso, a delimitação do estudo realizado apenas na unidade da Bacia de Campus, em Macaé/RJ, e o setor escolhido foi o de projetos que está localizado no departamento de construção e manutenção.

O roteiro de entrevista foi constituído por um total de dez entrevistados e a pesquisa foi realizada entre os dias 14 a 23 de maio de 2016. 


\subsection{Coleta de Dados}

Com o objetivo de obter melhores resultados, a coleta de dados foi obtida através da entrevista que seguiu um roteiro estruturado, previamente, desenvolvido para a organização das ideias e, com isso, conseguir uma melhor compreensão dos dados sobre o estudo.

\subsection{Tratamento dos Dados}

Os dados foram coletados e armazenados para que sejam feitas as apurações e as interpretações do mesmo.

O autor do estudo procurou buscar anotar o máximo de informações relevantes para que depois de condensá-las em formato "escrita", na pesquisa exploratória, elas fossem desenvolvidas, assim, gerando as informações sobre o entendimento do estudo. Além disso, o volume de anotações e observações variaram de acordo com a evolução de cada entrevistado.

\subsection{Limitações do Método}

Nesse tipo de coleta de dados, por meio da pesquisa qualitativa, podemos identificar e listar algumas limitações, relacionadas abaixo:

- Problema com relação ao agendamento da entrevista, pois podem ocorrer imprevistos de acordo com a dinâmica da rotina do entrevistador e do entrevistado.

- As entrevistas podem ser realizadas através de contato telefônico, redes sociais, email ou até mesmo de forma informal, fora de um ambiente adequado para manter a qualidade da entrevista, portanto, essas formas de contato podem atrapalhar a veracidade dos dados coletados.

- Por ser uma entrevista em si, isso pode acarretar em alguns "desvios" de assunto, assim, ocasionando a perda do foco da pesquisa.

- As respostas podem ser tendenciosas, pois os entrevistados serão pessoas escolhidas de acordo com a acessibilidade de contato.

O autor do estudo pretende diminuir essas interferências da pesquisa qualitativa através de algumas ações como: preparo prévio do roteiro de 
entrevista, imparcialidade na elaboração das perguntas, foco nas perguntas sem distorções de outros assuntos não pertinentes, agendamento das entrevistas e deslocamento para a delimitação do estudo. 


\section{Apresentação e análise dos resultados}

Este capítulo está ordenado em duas seções que apresentam e discutem as principais informações e seus resultados alcançados. Sendo assim, na primeira seção descreve a organização "Petrobras" e na segunda seção descreve os resultados da análise.

\subsection{A Organização}

O Petróleo Brasileiro S/A (Petrobras) é uma organização pública de capital aberto tendo o Governo brasileiro como seu principal acionista. Além disso, a empresa possui operações em diversos países pelo mundo e com as suas principais áreas de atuação como: petróleo; gás e energia; distribuição; petroquímica e fertilizantes; biocombustível e transporte e comercialização.

No Brasil, a Petrobras possui diversas unidades espalhadas por diversas regiões, sendo que a sua principal operação está localizada na unidade da Bacia de Campus que fica na cidade de Macaé, no norte fluminense, do Estado do Rio de Janeiro, todavia, a área administrada pela unidade vai desde, aproximadamente, da cidade de Arraial do Cabo/RJ até imediações da cidade de Vitória/ES.

$\mathrm{Na}$ cidade de Macaé/RJ encontram-se as principais atividades operacionais da empresa no País, em uma região extremamente abrangente (Bacia de Campus), portanto uma região estratégica e de muita importância para a estatal no gerenciamento, por exemplo, das principais tecnologias "offshore" experimentadas e desenvolvidas através de novos projetos voltados à produção e exploração de sua matéria bruta. 


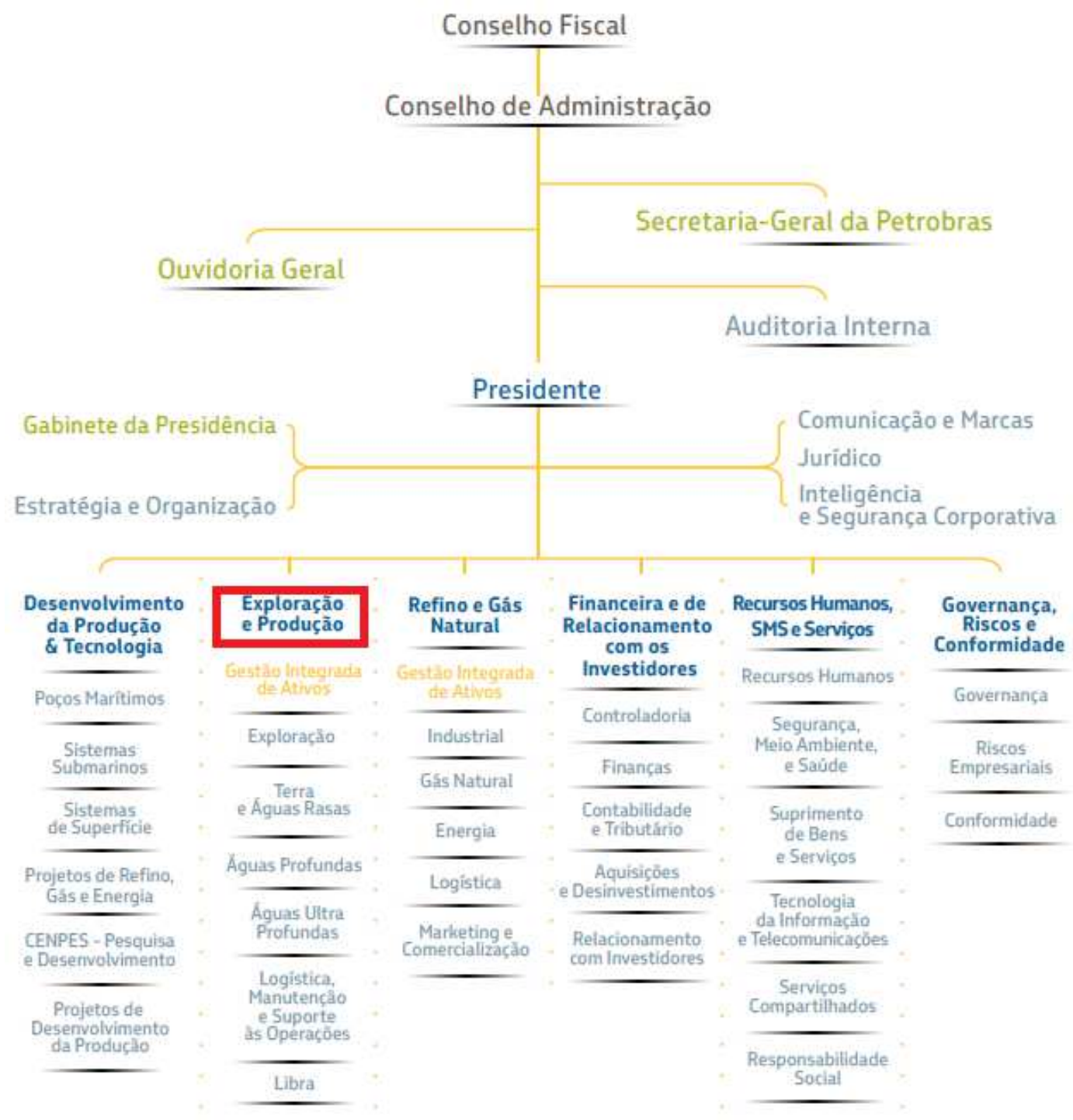

Figura 5 - Organograma da empresa. Fonte: Site da Petrobras.

$\mathrm{Na}$ ilustração acima, destaca-se a área onde a pesquisa foi explorada, portanto, a área de "Exploração e Produção" (E\&P), da Bacia de Campus, foi delimitada ao departamento de Construção e montagem, dentro da área de "Exploração", no setor de projetos, entretanto, a empresa está passando por diversas mudanças internas que podem afetar no seu organograma atual.

\subsection{Descrição e análise dos resultados das entrevistas}

\subsubsection{Perfil dos entrevistados}


As entrevistas seguiram buscando informações sobre os grupos pertencentes dos entrevistados, suas opiniões e percepções diante do fenômeno. Portanto, dois perfis de entrevistados foram selecionados para a execução das entrevistas. Sendo o primeiro perfil composto pelos celetistas, concursados, que ocupam cargos de perfil administrativo e o segundo que, também, ocupam cargos administrativos, contudo, são os terceirizados, funcionários contratados, que não são funcionários contratados através de concurso público.

Esses entrevistados possuíam diferentes tipos de estado civil (solteiros, casados e um divorciado), experiências distintas de tempo de contrato com a Petrobras que varia entre os três anos para os mais jovens e 41 anos para o mais experiente, além disso, os entrevistados possuem idades entre 25 a 60 anos, sendo nove do sexo masculino e um do sexo feminino. Com isso, a escolha dos perfis buscou levantar informações sobre a influência do absenteísmo dos grupos na produtividade do departamento, da Petrobras, de construção e montagem da unidade da Bacia de Campus em Macaé/RJ. Vejamos abaixo a quantificação e os cargos (ocupação) dos entrevistados:

- 5 Técnico de projetos, construção e montagem (celetistas) responsável pela fiscalização técnica de projetos.

- 3 Técnico de administração e controle (celetista) - responsável por fiscalizar os processos administrativos.

- 1 Técnico administrativo de materiais (terceirizado) - responsável pela análise da documentação geral dos materiais da área externa (plataforma).

- 1 Técnico de manutenção de materiais (celetista) - responsável em auxiliar a análise de contratos de materiais.

Portanto, a escolha desses dois perfis de grupos foi para garantir a imparcialidade das informações, pois a visão dos celetistas e a visão dos terceirizados foram importantes para o entendimento da ação do fenômeno no processo de produção das atividades administrativas.

\subsection{Limitações da pesquisa}

Uma das maiores dificuldades encontrada no desenvolvimento da pesquisa foi quando, ao decorrer das entrevistas, constatou-se que alguns dos 
entrevistados, às vezes, entravam em contradição, pois, talvez, ficassem um pouco desconfortáveis em expor detalhes de sua rotina de trabalho, porém, nada que muda-se o entendimento das informações. Os mesmos estão inseguros com relação às mudanças internas que a Petrobras vem sofrendo, intensamente, na Bacia de Campus em Macaé/RJ, como por exemplo, a extinção de alguns setores, segundo um dos entrevistados em uma conversa informal. Entretanto, todos os entrevistados responderam todas as perguntas e descreveram, ao máximo, do que percebiam sobre o tema no seu setor.

Infelizmente, não foi possível entrevistar um maior número de funcionários do gênero feminino por conta da dificuldade de acesso em adquirir os poucos contatos, pois o setor demanda da maioria absoluta de homens. Portanto, talvez, a justificativa seja porque que a maioria dos funcionários trabalham embarcados, nas plataformas (área externa), onde a presença feminina é praticamente inexistente.

Nivel do cargo por gênero

TOTAL

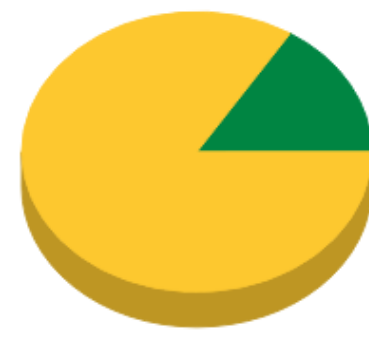

Dados da Petrobras Controladora
$83.9 \%$

Homens

47.744

$16.1 \%$

Mulheres

9.130
Empregados por nivel do cargo e gênero NIVELL MÉDIO

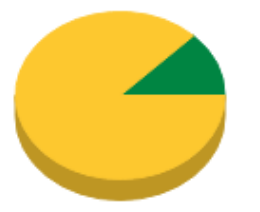

$87.3 \%$

Homens

30.566

$12.7 \%$

Mulheres

4.433
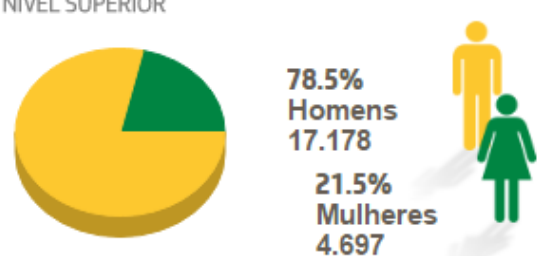

Figura 6: Perfil dos profissionais da Petrobras (gênero). Fonte: Site da Petrobras.

Para entendermos melhor a pequena presença do gênero feminino na delimitação do estudo (departamento de construção e montagem), vejamos a Figura 6, pois, assim, podemos concluir que a Petrobras possui a sua maior parte dos seus colaboradores constituídos pelo gênero masculino em todos os níveis de hierarquia da empresa. Além disso, a participação dos funcionários terceirizados foi muito abaixo do esperado, pois com a crise financeira da empresa, ela teve que realizar diversos "cortes" em diversas áreas de sua 
atuação. Sendo assim, uma das políticas adota pela empresa para redução dos custos além dos cortes dos investimentos, infelizmente, foi à diminuição, do seu quadro de funcionários terceirizados, assim, publicado pela revista online "Exame".

\subsection{Descrição e análise dos resultados}

Primeiramente, com relação ao tema "absenteísmo", foi perguntado aos entrevistados sobre o seu real entendimento sobre o assunto, e a maior parte desses entrevistados responderam que "sim", como ilustra a Figura 7, e isso revela que o tema sobre o fenômeno era de compreensão desses profissionais, pois eles definiram o seu entendimento, próximo a definição referenciada através do autor Chiavenato (2010), de como se descreve esse fenômeno, assim, argumentando sobre os efeitos negativos da prática do absenteísmo para o setor e a empresa como um todo.

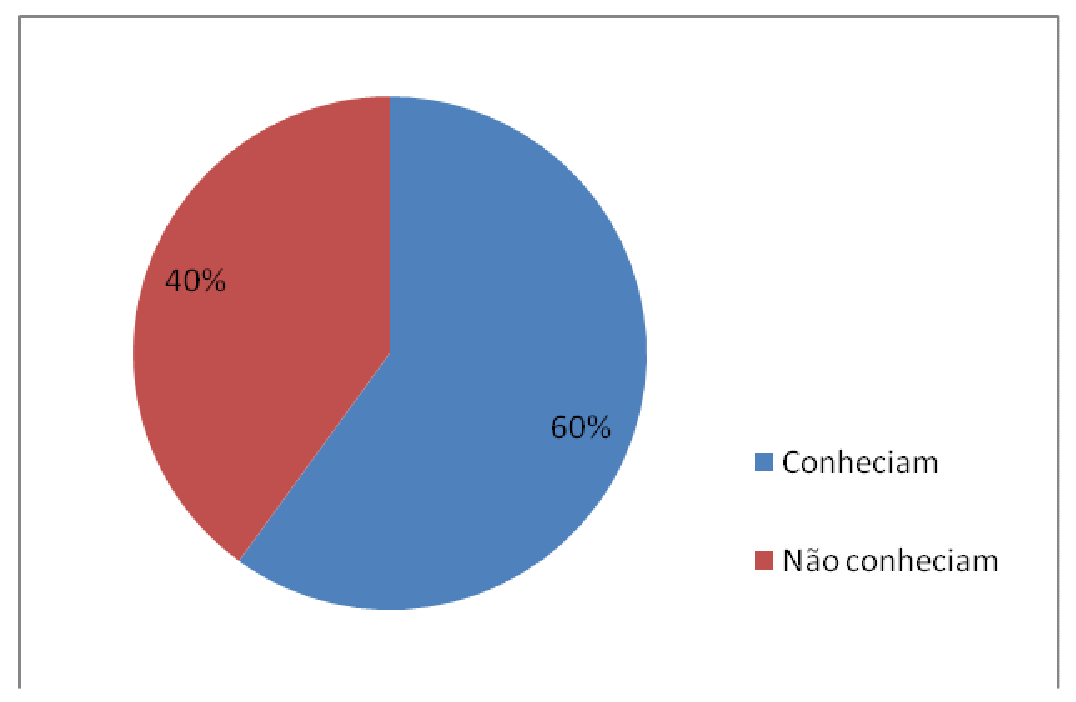

Figura 7: Percentual de entrevistados que conheciam o tema "absenteísmo".

Em seguida, os entrevistados foram questionados sobre a sua ausência em sua vida profissional, em especial, na atual empresa, Petrobras. Os entrevistados, em sua grande maioria, responderam que já se ausentaram no posto de trabalho. Portanto, vejamos a Figura 8 ilustrada: 


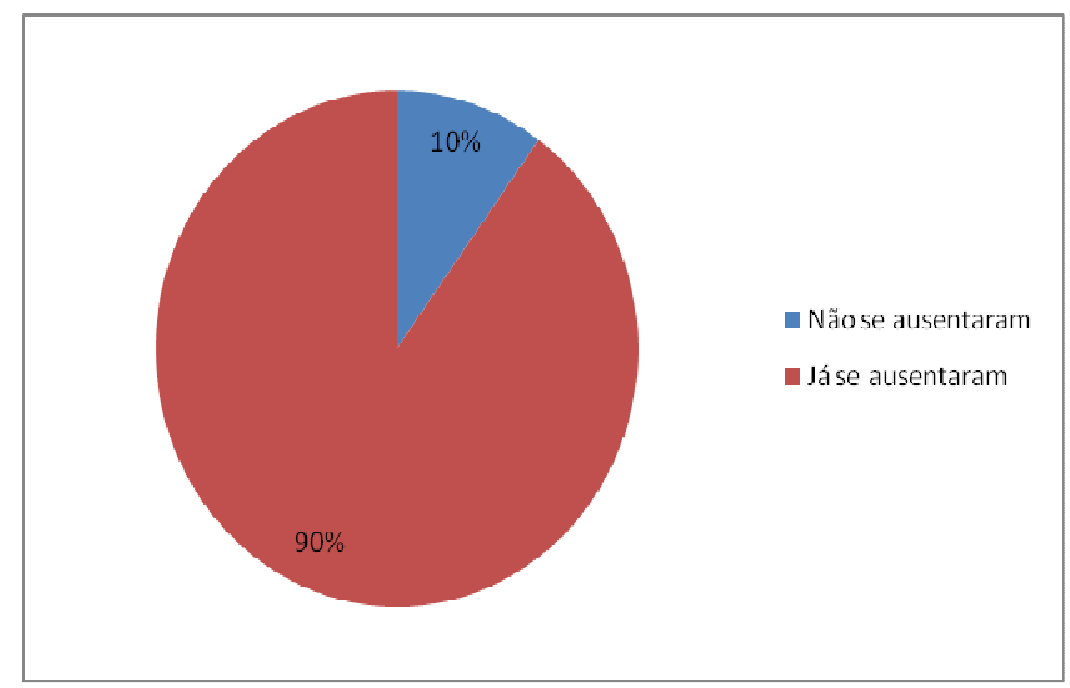

Figura 8: Percentual de entrevistados que já se ausentaram ou não no trabalho.

A partir disso, foram narrados os principais motivos que levaram os entrevistados a se ausentarem, tais como: a decisão pessoal de não comparecer ao trabalho na segunda e/ou sexta-feira, fenômeno natural (dias chuvosos), deslocamento de sua residência até o local de trabalho (distância), problemas com o trânsito (acidentes em vias de acesso), motivos pessoais, fadiga, problemas de saúde (doenças), motivos de viagens (principalmente, na volta dos feriados prolongados), atrasos e acidente de trabalho. Assim, entendemos a compreensão de DuBrin (2003) que definiu a motivação como um meio pelo qual o comportamento é estimulado e incentivado.

Com relação ao prejuízo e a modificação da rotina de trabalho por causa das ausências dos colegas de trabalho, a maioria dos entrevistados disseram que "sim", pois afeta a rotina de trabalho, eventualmente, portanto, diversas vezes os entrevistados exemplificavam com situações de cotidiano, por exemplo, eles informavam que o setor funcionava, em sua grande parte, com diversos documentos fiscais e de projetos, portanto, se um funcionário se ausentasse do seu posto de trabalho, o processo produtivo sofreria atrasos e isso ocasionava em interrupção dos despachos desses documentos. Portanto, entendemos os autores Cohen e Fink (2003), que defendem que toda organização está interessada na produtividade dos seus profissionais. Assim, vejamos a ilustração da Figura 9 para melhor compreensão da análise da pesquisa. 


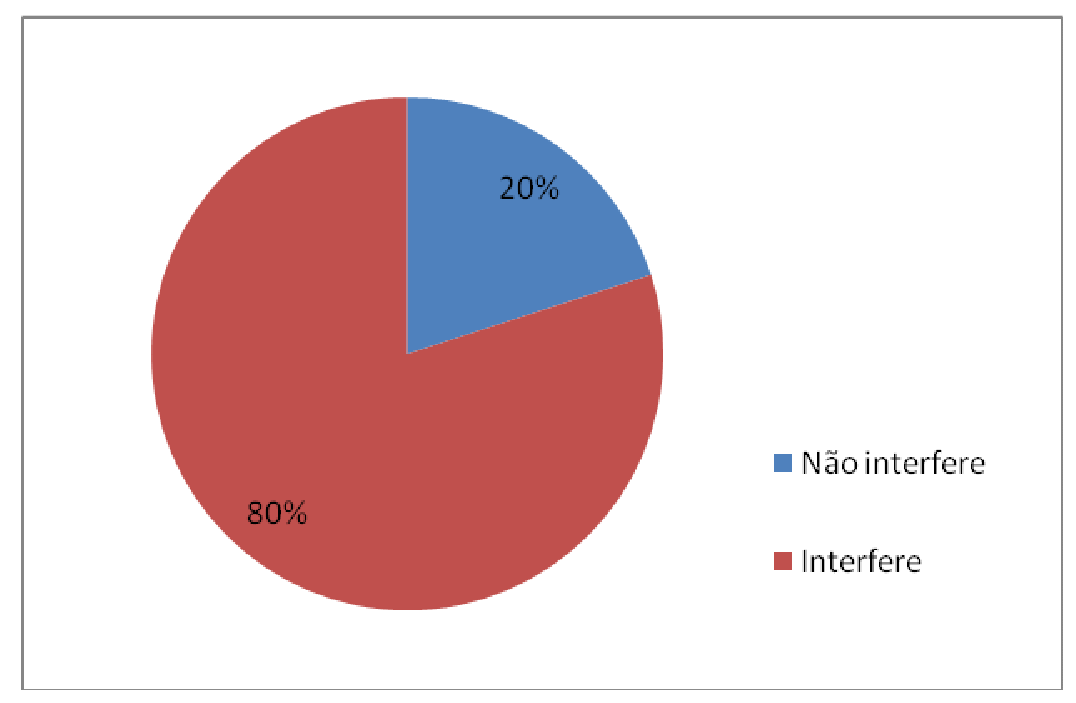

Figura 9: Percentual de entrevistados que entende que de alguma forma o fenômeno absenteísmo interfere no desenvolvimento do trabalho.

Outro ponto questionado foi a respeito da relação e diferenciação dos grupos formais, sejam eles formados por grupo de funcionários celetistas ou grupo de funcionários terceirizados. A partir disso, os entrevistados se mostraram com entendimentos divididos, pois, a metade deles informou que há "sim" a ausência maior do grupo de celetistas sobre o grupo de terceirizados por causa da estabilidade empregatícia e uma maior "facilidade" de reposição das horas perdidas através da utilização das possíveis "folgas" disponíveis, assim, fazem com que a compreensão do "status de grupo" descrito por Cohen e Fink (2003) seja entendida em sua literatura, por outro lado, os demais entrevistados disseram que não há esse tipo de diferenciação entre os grupos quanto ao absenteísmo, pois eles entendem que seja uma prática que independentemente do grupo pertencente, a ausência quando praticado é realizado por todos sem distinção de grupos de celetista e terceirizado. Além disso, com relação à marcação de pontos de entradas e saídas (intervalo para almoço ou de expediente), a maioria dos entrevistados não vêem maior frequência da ausência sendo realizada por um determinado grupo.

Para a maioria dos funcionários, no ponto de vista ético, eles entenderam que a maior parte dessas ausências, dos colegas no posto de trabalho, sejam eles por motivos inevitáveis, pois eles interpretam que não há ausência de "má fé", dos seus colegas, por entenderem que cada um possui o seu motivo pessoal de se ausentar, seja qualquer que for o motivo. Por causa disso, é muito difícil julgar os seus colegas de trabalho por essa ótica de percepção, portanto, Chiavenato (2010) já compreendia as ausências no trabalho dos profissionais 
por dois tipos de motivos que são os motivos evitáveis e os inevitáveis. Assim, vejamos a ilustração da Figura 10 que condensa o entendimento dos entrevistados.

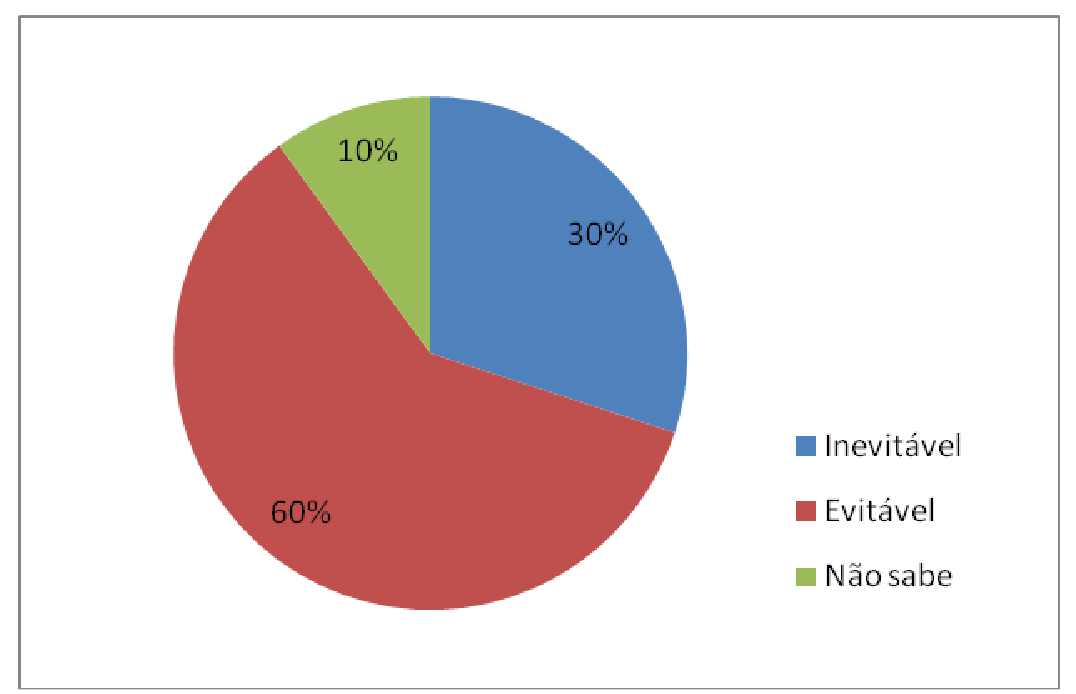

Figura 10: Percentual de respondentes que acreditam que as ausências, dos colegas de trabalho, sejam realizadas por motivo evitável ou inevitável.

Em seguida, no questionamento sobre se existia diferenciação grupos de gênero (homens e mulheres) e faixa etária (jovens e mais velhos), por exemplo, os entrevistados entenderam que não há diferenciação entre esses grupos diversificados, pois eles compreendem que apesar das mulheres, eventualmente, faltaram mais que os homens por causa de questões, em sua maioria, por motivos familiares, e os mais jovens, também, eventualmente, se ausentarem mais que os mais experientes por motivo "extra-profissional" (compromisso acadêmico, por exemplo), esses grupos não são percebidos, de fato. Assim, essa diversidade de gênero e de idade interpreta-se de uma maneira superficial através das características biográficas definidas por Robbins, Judge e Sobral (2010).

Também foi dito, por todos os entrevistados, que existe, sim, períodos do ano em que o absenteísmo é mais evidente, como por exemplo: períodos comemorativos (carnaval e final de ano) e feriados prolongados, principalmente.

Posteriormente, os entrevistados responderam a seguinte questão, se em sua rotina de trabalho, eles percebiam algum tipo de conversa, comentário ou conversa "paralela", entre os colegas de trabalho, sobre a ausência de algum colega de trabalho, pois bem, a maior parte dos funcionários disse que "sim", pois muita das vezes os comentários sobre a falta ou atraso do funcionário é 
mais com relação à preocupação com o mesmo e não, necessariamente, por exemplo, conversas "ofensivas" para o colega de trabalho que se ausentou seja qual for o motivo. No entendimento dos autores Bowditch e Buono (2006), a comunicação interpessoal de trabalho é compreendida a todo momento como um processo de interação entre os indivíduos no ambiente de trabalho. Vejamos na ilustração a seguir:

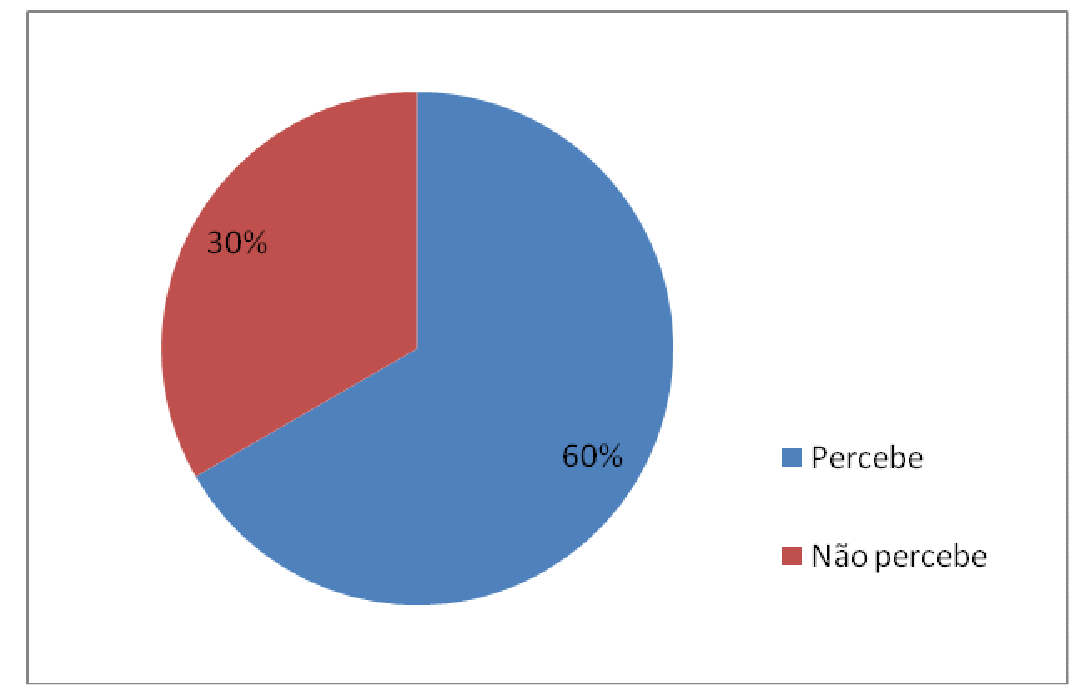

Figura 11: Percentual de entrevistados que percebem a comunicação interpessoal entre os funcionários sobre a ausência dos colegas de trabalho.

A relação entre o absenteísmo e a produtividade foi narrada por todos os entrevistados como um fenômeno prejudicial ao setor, consequentemente, a organização como um todo, pois, com a narração de suas diferentes experiências, eles descreviam as suas rotinas de trabalho sendo prejudicadas (com diferentes intensidades), portanto, os processos administrativos do setor ficavam atrasados, assim, gerava um desconforto entre alguns colegas que, eventualmente, abandonam seus postos de trabalho para ocuparem outras funções com intuito de suprir uma possível demanda de trabalho. Além disso, não apenas os funcionários se sentem incomodados, em sua maioria, como eles percebem a influência "negativa", também, na gestão de sua chefia, pois eles acreditam que o seu gestor fica, em alguns momentos, com dificuldade de planejar a rotina de trabalho, porque dependendo do funcionário que esteja ausente, um processo importante é interrompido, assim, atrasando todos os processos. Essa percepção é compreendida pela literatura de Bowditch e Buono (2006) como uma relação a interpretações audiovisual dos indivíduos. Sendo assim, todos os funcionários foram unânimes ao informar, posteriormente, que o 
gestor deve ficar atento, sim, a presença desse fenômeno em sua equipe de trabalho para que o ele possa traçar um "plano de contingência", por exemplo, para que o as ausências não afetem tanto na produtividade e na harmonia entre os funcionários de sua equipe.

Um ponto que chamou a atenção do entrevistador e que gerou "polêmica" foi com relação à "bonificação" e a "punição" para os funcionários presentes e os ausentes no seu posto de trabalho, respectivamente, sendo proposta como uma possível ação no combate ao absenteísmo. No caso da bonificação, a maior parcela dos entrevistados foi contra esse tipo de ação, pois eles entenderam que essa possível ação não se aplicaria como uma ferramenta de incentivo por ser uma obrigação do profissional perante o seu contrato de trabalho, por outro lado, na questão da punição houve, praticamente, uma divisão entre alguns entrevistados que são a favor e outros que são contra esse tipo de ação, no caso dos que apóiam a ação, eles entendem que o funcionário que se atrase ou se ausente, eventualmente, após um diálogo com sua chefia e, assim, permanecendo a prática esse indivíduo deve ser punido de fato, já os funcionários que foram contra, eles alegam que a punição já é aplicada com o desconto no salário do indivíduo, portanto, é satisfatório. Vejamos nas Figuras 12 e 13, respectivamente, a seguir:

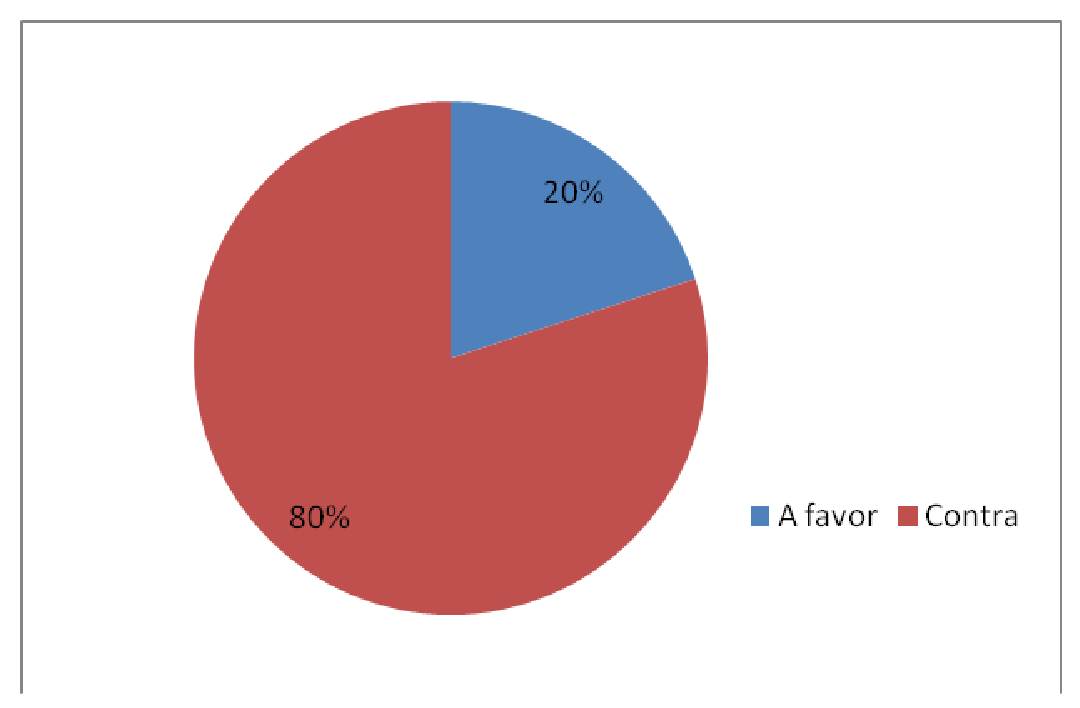

Figura 12: Percentual de entrevistados a favor e contra uma possível ação de "bonificação" aos funcionários que pouco se ausentam em seus postos de trabalho. 


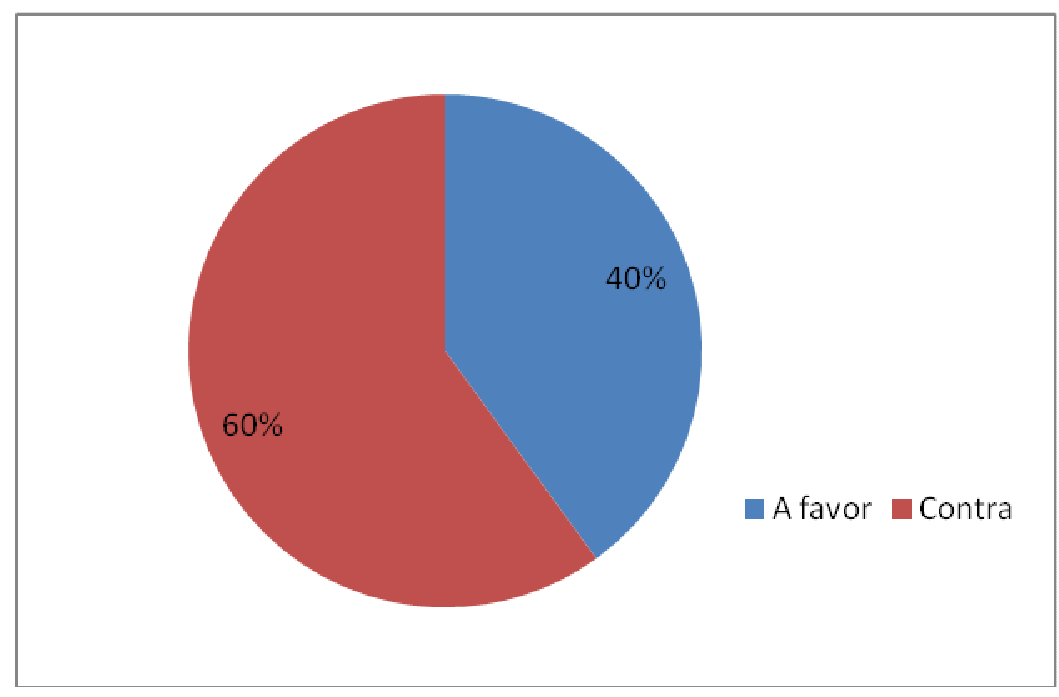

Figura 13: Percentual de entrevistados a favor e contra uma possível ação de "punição" aos funcionários que pouco se ausentam em seus postos de trabalho.

Algumas ações de incentivo ao funcionário foram exemplificadas como: tratamento de psicoterapia, exercício laboral, campanhas de conscientização sobre a importância do funcionário para a organização, estrutura segura e opção de transporte aos funcionários, por exemplo, foram descritas, pelo entrevistador. A partir do entendimento dessas ações, todos os entrevistados concordaram com essas iniciativas, exemplificadas, e afirmaram que todas essas ações são praticadas pela empresa, com exceção de um entrevistado, do grupo terceirizado, que descreveu que, infelizmente, ele não tem a oportunidade de utilizar o transporte particular da empresa, pois o mesmo informou que apenas é disponibilizado aos funcionários celetistas, entretanto, nas demais ações, ele de fato confirmou que são praticadas pela Petrobras.

Por fim, os funcionários foram questionados sobre como eles se sentem no aspecto motivacional para evitar a prática do fenômeno do absenteísmo. Para DuBrin (2003), essa motivação é o meio pelo qual o comportamento é estimulado. A partir desse entendimento, analisando os entrevistados, eles em sua grande maioria se sentiram, sim, focados e motivados no seu ambiente de trabalho, pois eles informaram que se sentem úteis para a empresa, o ambiente de trabalho é bem agradável (estrutura e colegas de trabalho), eles possuem um orgulho de trabalhar na Petrobras, entretanto, outros poucos entrevistados disseram que por conta da diminuição da demanda do trabalho, em sua rotina, muito por conta da crise econômica da empresa e do País, e por estarem participando tarefas e atividades rotineiras e pouco flexíveis, na organização, 
esses funcionários não se sentem tão motivados para uma eventual prática do absenteísmo. Vejamos a ilustração da Figura 14 abaixo:

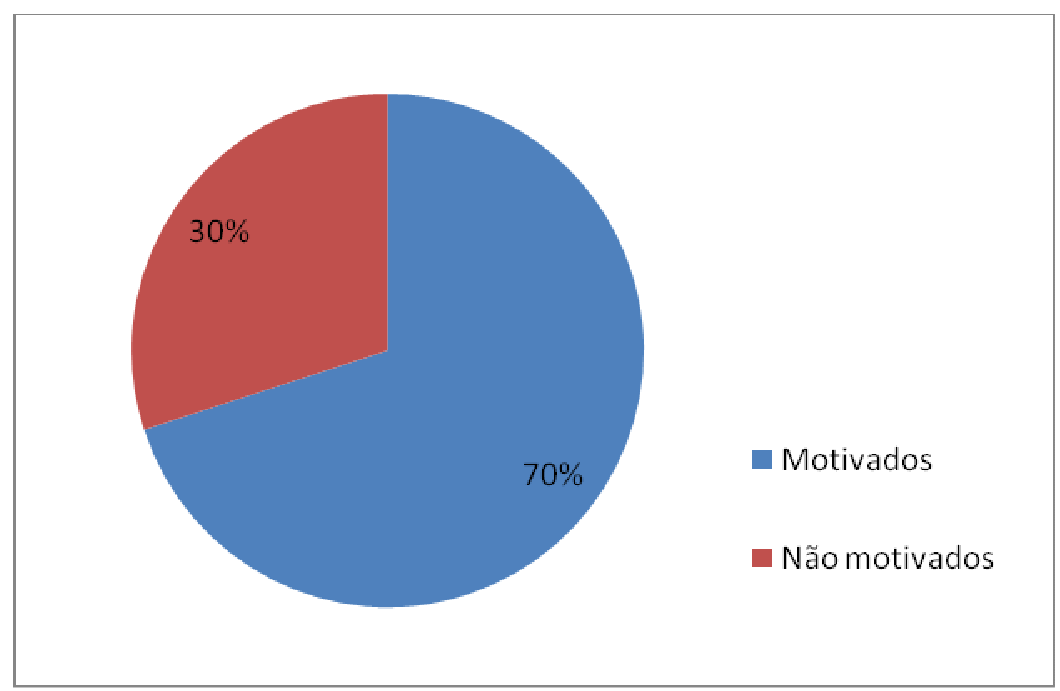

Figura 14: Percentual de entrevistados que se sentem motivados para não se ausentarem no seu ambiente de trabalho.

$\mathrm{Na}$ literatura do autor Chiavenato (2010), e de acordo com a teoria motivacional de Maslow, esses funcionários que se encontram "motivados" possuem a necessidade de autorealização por já se sentirem satisfeitos e, provavelmente, estarem em estágio de busca de sua realização profissional, por outro lado, os que se consideram "desmotivados", eles se encontram com a necessidade de estima, talvez, por não se sentirem úteis ou satisfeitos com a função que exercem, atualmente. Já na teoria de Herzberg, tanto os funcionários motivados e os desmotivados, eles se encontram no fator motivacional que é correspondente a necessidade de autorealização e de estima, respectivamente, da teoria de Maslow. 


\section{Conclusões e recomendações para novos estudos}

Esse trabalho pretendeu investigar como o fenômeno absenteísmo influencia no comportamento dos grupos formais, do departamento de Construção e Montagem, na Unidade da Bacia de Campus da Petrobras, assim, o estudo buscou relacionar o comportamento e o absenteísmo dos indivíduos e seus respectivos grupos, com a revisão literária do comportamento organizacional e de gestão de pessoas, assim, identificando a influência do absenteísmo no ambiente de trabalho dos entrevistados. O foco do estudo recaiu sobre o comportamento dos grupos. Tal questão se mostra importante na medida em que, nas organizações, em geral, as tarefas administrativas são caracterizadas por pequenos processos, no qual um profissional, muitas vezes, depende da colaboração do outro colega de trabalho para a conclusão do mesmo.

Para aprofundar a análise pretendida, investigou-se a perspectiva de Robbins, Judge e Sobral (2010), Bowditch e Buono (2006), Chiavenato (2010 e 2011), DuBrin (2003), Cohen e Fink (2003) e de Gil (2002) para fazer uma melhor compreensão do comportamento e o absenteísmo da limitação do estudo, dos grupos formais, com a literatura acadêmica.

Para atingir os objetivos pretendidos realizou-se pesquisa exploratória e descritiva. Foram realizadas dez entrevistas com funcionários da Petrobras nas funções "técnicas" administrativas. Os dados foram tratados através do referencial teórico e das informações coletadas das entrevistas.

Dentre as principais questões abordadas concluiu-se que a maior parte dos funcionários, eventualmente, já se ausentou no seu posto de trabalho, especialmente, na Petrobras. Entretanto, eles ainda se sentem motivados, em sua maioria, a evitar essas ausências a fim de melhorar o seu desempenho profissional, assim, consequentemente, a produtividade do setor. Para isso, muitas das causas das ausências teriam que ser diminuídas, como por exemplo, os motivos pessoais, tais como os problemas e os compromissos, pois essa variável foi a mais citada como a principal causa para justificar os atrasos e as ausências no seu posto trabalho. 
Finalmente, entende-se que a presença do fenômeno absenteísmo, atrapalha no desenvolvimento dos processos administrativos, pois com a ausência de qualquer que seja o funcionário, celetista ou terceirizado, isso significa atrasos na entrega da produção administrativa e mudanças no planejamento da chefia na gestão de sua equipe, além disso, isso gera algum tipo de desconforto entre os demais indivíduos, mudança de comportamento, pois esses profissionais são realocados, temporariamente, assim, eles acumulam tarefas e atividades extras dependendo da demanda de trabalho do setor.

\subsection{Sugestões e recomendações para novos estudos}

Como desdobramentos futuros, essa linha de estudo pode ser desenvolvida através de investigação sobre o tema do absenteísmo, além disso, deve-se ampliar as entrevistas para um maior número de entrevistados, principalmente, grupo do gênero feminino e o grupo de terceirizados.

Recomenda-se que esse tema seja abordado não apenas pela gestão do setor, delimitado, e sim com a integração com os demais departamentos.

Sugere-se que sejam realizadas novas pesquisas sobre o tema "absenteísmo" nas organizações, seja ela pública ou privada, a fim de identificar quais possíveis ações poderiam ser incrementadas para diminuição do fenômeno nas organizações.

Por fim, recomenda-se, também, que sejam desenvolvidas pesquisas com a utilização de indicadores para mensurar os impactos desse fenômeno nos resultados da organização. 


\section{Referências Bibliográficas}

ARAUJO, Lucas. A distinção entre servidores públicos e empregados públicos. Disponível em: <http://lucasecao.jusbrasil.com.br/artigos/213304655/a-distincao-entreservidores-publicos-e-empregados-publicos>. Acesso em: 21 mar. 2016.

BOWDITCH, James L.; BUONO, Anthony F. Fundamentos de Comportamento Organizacional. Tradução de Luiz Henrique Baptista Machado. 6.ed. Rio de Janeiro: LTC, 2006.

CHIAVENATO, Idalberto. Gestão de pessoas. 3.ed. Rio de Janeiro: Elsevier, 2010.

CHIAVENATO, Idalberto. Introdução à Teoria Geral da Administração. 8.ed. Rio de Janeiro: Campus, 2011.

COHEN, Allan C.; FINK L. Stephen. Comportamento Organizacional: Conceitos e Estudos de Casos. Tradução de Maria José Cyhlar Monteiro. 7.ed. Rio de Janeiro: Campus, 2003.

DUBRIN, Andrew J. Fundamentos do comportamento Organizacional. Tradução de James Sunderland Cook. São Paulo: Thomson, 2003.

GIL, Antonio C. Como Elaborar Projetos de Pesquisa. 4.ed. São Paulo: Atlas, 2002.

LUDERS, Germano. Petrobras planeja outra rodada de demissões de terceirizados. Disponível em: <http://exame.abril.com.br/negocios/noticias/petrobras-planeja-outra-rodada-dedemissoes-de-terceirizados>. Acesso em: 20 mai. 2016.

Petróleo Brasileiro S/A. Bacia de Campus. Rio de Janeiro, 2016. Disponível em: 
$<$ http://www.petrobras.com.br/pt/nossas-atividades/principais-

operacoes/bacias/bacia-de-campos.htm>. Acesso em: 21 mar. 2016.

PIRES, Beatriz Calero G. As empresas estatais e o controle societário do Estado. Disponível em: <http://www.editorajc.com.br/2012/09/as-empresasestatais-e-o-controle-societario-do-estado/>. Acesso em: 10 mar. 2016.

Programa Nacional de Gestão Pública e Desburocratização. Empresas Estatais. Rio de janeiro, 2009. Disponível em: $<$ http://www.gespublica.gov.br/projetos-acoes/pasta.2009-07-

15.5584002076/Empresas\%20Estatais.pdf>. Acesso em: 21 mar. 2016.

REVISTA PROTEÇÃO. Absenteísmo: $45 \%$ das faltas ao trabalho não são justificadas, diz estudo. Disponível em: <http://www.protecao.com.br/noticias/estatisticas/absenteismo:_45_das_faltas_a o_trabalho_nao_sao_justificadas,_diz_estudo/J9y5Acjy/3285>. Acesso em: 14 mar. 2016.

RH PORTAL. Absenteísmo. Disponível em: < http://www.rhportal.com.br/artigos-rh/absentesmo/>. Acesso em: 20 jun. 2016.

ROBBINS, Stephen P.; JUDGE, Timothy A.; SOBRAL, Filipe. Comportamento Organizacional: Teoria e prática no contexto brasileiro. Tradução de Rita de Cássia Gomes. 14.ed. São Paulo: Pearson Prentice Hall, 2010.

SALOMÃO, K. As 7 empresas brasileiras entre as maiores do mundo em 2015. Disponível em: <http://exame.abril.com.br/negocios/noticias/as-maioresempresas-brasileiras-em-2015-segundo-a-fortune>. Acesso em: 11 set. 2015.

SOUZA, Wagner J. Como surgiu a figura do servidor público. Disponível em: <http://www.ugt.org.br/index.php/post/6437-Como-surgiu-a-figura-do-servidorpublico>. Acesso em: 10 mar. 2016. 


\section{Apêndice}

\section{Roteiro das entrevistas}

1) Qual o seu cargo na Petrobras?

2) Há quantos anos você trabalha na Petrobras?

3) Qual seu tipo de contrato (vínculo) com a Petrobras? (celetista, terceirizado ou temporário)

4) Você sabe o que é "absenteísmo"? Qual sua opinião sobre o absenteísmo no seu ambiente de trabalho?

5) Em algum momento você já se ausentou ou se atrasou na sua vida profissional? E na Petrobras?

6) Se "sim", na pergunta anterior, quais foram os motivos que provocaram a sua ausência no seu trabalho? (ex. decidir de não ir trabalhar na seg. e/ou sex., fenômeno natural (chuva), relação interpessoal, deslocamento (distância), violência, trânsito etc)

7) Esse fenômeno "absenteísmo" de alguma forma já atrapalhou a sua rotina de trabalho ou a de seus colegas? Se sim, cite exemplo(s).

8) Em sua opinião, com relação aos grupos de celetistas e terceirizados, você percebe se o absenteísmo está mais presente em algum desses grupos? Existe diferenciação entre os grupos quando se trata desse tema? Porque você acha isso?

9) Com relação ao intervalo para o almoço, marcação de ponto nas entradas e saídas de expediente, por exemplo. Você percebe a ausência, no posto de trabalho, por indivíduos de um determinado grupo? Comente.

10) No ponto de vista ético, você acredita que as ausências dos funcionários do seu departamento são evitáveis ou inevitáveis? Por quê?

11) Você acredita que as mulheres, por exemplo, se ausentam mais que os homens no trabalho? Ou que os mais velhos faltam mais que os mais jovens? Ou vice-versa? Se sim, por quê?

12) Em sua opinião, você percebe que em determinado(s) período(s) do ano o absenteísmo é mais evidente no seu local de trabalho? Dê exemplo(s). 
13) Na sua rotina você percebe algum tipo de conversa entre as pessoas do seu ambiente de trabalho sobre a ausência ou atraso de algum colega? Comente.

14) Em sua opinião, o absenteísmo pode de alguma forma atrapalhar a produtividade da empresa? Por quê?

15) Em sua opinião, numa rotina de trabalho, a ausência dos funcionários de alguma forma atrapalha a gestão de sua chefia? Comente.

16) Você acredita que o seu gestor deve ficar atento a presença desse fenômeno entre os funcionários de sua equipe? Por que você acredita nisso?

17) Você é a favor ou contra a utilização de algumas ações como, por exemplo, a "bonificação" para os funcionários presentes, no posto de trabalho, e a "punição" para os funcionários ausentes como instrumento de incentivo no combate ao absenteísmo? Por quê?

18) Algumas ações como o tratamento de psicoterapia, exercício laboral, campanhas de conscientização sobre a importância do funcionário para a organização, estrutura segura e opção de transporte aos funcionários, por exemplo, seriam algumas das diversas formas de incentivar o funcionário a ir ao trabalho. Algumas dessas ações são praticadas pela Petrobras? A empresa pratica outras ações semelhantes? Dê exemplo(s).

19) Você, hoje, se sente focado no seu ambiente de trabalho para evitar as ausências na sua vida profissional? Por quê? 